\title{
DYNAMIC IDENTIFICATION OF THE SANSEPOLCRO (ITALY) MUSEUM AND THE WALL SUPPORTING THE RESURRECTION OF CHRIST BY PIERO DELLA FRANCESCA
}

\author{
G. Lacanna ${ }^{1}$, M. Ripepe ${ }^{1}$, P. Deguy ${ }^{1}$, L. Orti ${ }^{1}$, and M. Della Schiava ${ }^{1}$ \\ ${ }^{1}$ University of Firenze \\ Via G. La Pira ${ }^{\circ} 4$, Firenze, Italy \\ e-mail: giorgio.lacanna@unifi.it, maurizio.ripepe@unifi.it \\ e-mail: paulinedeguy@gmail.com, letizia.orti@unifi.it, massimo.dellaschiava@unifi.it,
}

\begin{abstract}
Dynamic identification is considered a powerful technique for testing the conservation status of buildings as their natural frequencies, damping and modal shapes are directly related to their rigidity and structural integrity. This issue is of crucial interest when historical structures are in area of high seismic level, as SanSepolcro city which has experienced earthquakes up to a maximum intensity of $I_{\max }=X M C S$ scale. The dynamic response is suitable for ancient structures because is performed by measuring ambient vibrations instead of actively shaking the building. The results obtained from dynamic tests might be used to validate the assumptions used in numerical modeling in order to reduce the uncertainties related to the soil-structure interaction and to the structural parameters. In this framework, we show how an automatic identification procedure can track in real-time the dynamic response of the museum in Sansepolcro (Italy) using operational modal analysis (OMA). The dynamic characteristics, of the SanSepolcro museum and the wall supporting the mural painting of Resurrection of Christ, were identified by installing a temporary network of 10 seismic sensors. The OMA technique was performed using enhanced frequency domain decomposition (EFDD) which has allowed to detect the first four modal shapes, damping and structural frequencies. The dynamic characteristics were used to calibrate a more realistic and reliable 3D-FEM numerical model. Integrating, the results of the dynamic indetification with 3D-FEM model analysis, has provided important information to understand the complicated system of connections between the existing walls.
\end{abstract}

Keywords: Dynamic Identification, Operational Modal analysis, Structural Health Monitoring 


\section{INTRODUCTION}

In recent few decades, Operational Modal Analysis (OMA), also known as Output Only or Ambient Vibration Test, has become a powerful tool for a wide range of applications in the field of civil engineering [1, 2, 3, 4]. The Output Only modal test represents an extraordinary alternative when the structures are too important to be artificially excited. This method takes advantages from natural sources of vibration (wind, traffic, sea waves etc.) instead of having to shake the structure artificially $[5,6]$. The difficulty associated with output-only test is that the measured response is often noisy and contains the characteristics of the structure as well as the characteristics of the unknown excitation force. So, the power of Output Only modal identification method is to distinguishing the structural modes from the ambient vibration [7, 8].

Dynamic characterization is a method for testing the health status of structure because its natural frequencies and mode shapes are directly related to its integrity $[9,10]$. The dynamic response of the buildings is increasingly growing when the functionality and the health status of the edifices have to be estimated. This issue is of crucial interest when historical structures are in area of high-medium seismic risk, as the SanSepolcro museum which is located in area with a medium seismic hazard (PGA $0.22 \mathrm{~g}$ ), i.e. the highest seismicity in Tuscany.

In this framework, we here present an application of the automatic Enhanced Frequency domain decomposition method $[11,12,13,14]$ to define the dynamic behaviour of the Museum in SanSepolcro and the wall supporting the Resurrection of Christ. The Resurrection is a mural painting painted during the Italian renaissance (1460 A.D) by Piero della Francesca and it is considered a masterpiece in the development of painting. The wall supporting the mural painting is located in the middle of room embedded by lateral walls (Figure 2a).

The dynamic identification was used to derive a more accurate 3D FEM numerical model [15 - this volume] able to reproduce the real dynamic behaviour of the building. Integrating, the results of the dynamic indetification with 3D FEM model analysis, has provided important information to understand the complicated system of connections between the existing walls of this historical building.

\section{DYNAMIC IDENTIFICATIO TEST}

The main aim of the seismic survey was to investigate the dynamic behaviour of the wall supporting the famous mural painting of Resurrection of Christ. Therefore, the ten seismic stations were installed in south - side area of the museum that contains the mural painting (Figure 1, 2).

The seismic survey presented in this work was carried out for 17 hours, from 9 to 10 November 2017, and with ten seismic stations (Figure 1,2). Each seismic station was equipped with 3-component seismometers: six stations with Lennartz 3D/5s seismometers (sensitivity 400 $\mathrm{V} / \mathrm{m} / \mathrm{s}$ and with a $5 \mathrm{~s}$ eigenperiod); three stations with Guralp CMG-6T seismometer (sensitivity $2400 \mathrm{~V} / \mathrm{m} / \mathrm{s}$ with a $10 \mathrm{~s}$ eigenperiod) and one station with a Guralp CMG-40T seismometer (sensitivity $800 \mathrm{~V} / \mathrm{m} / \mathrm{s}$ with a $30 \mathrm{~s}$ eigenperiod). Seismic data were digitized using a 24 bits Guralp CMG24 Digitizer at $100 \mathrm{~Hz}$, and the time synchronization between stations was achieved using GPS. The three stations were installed at ground level (Figure 1), the others seven stations were located on the roof (Figure 2). 


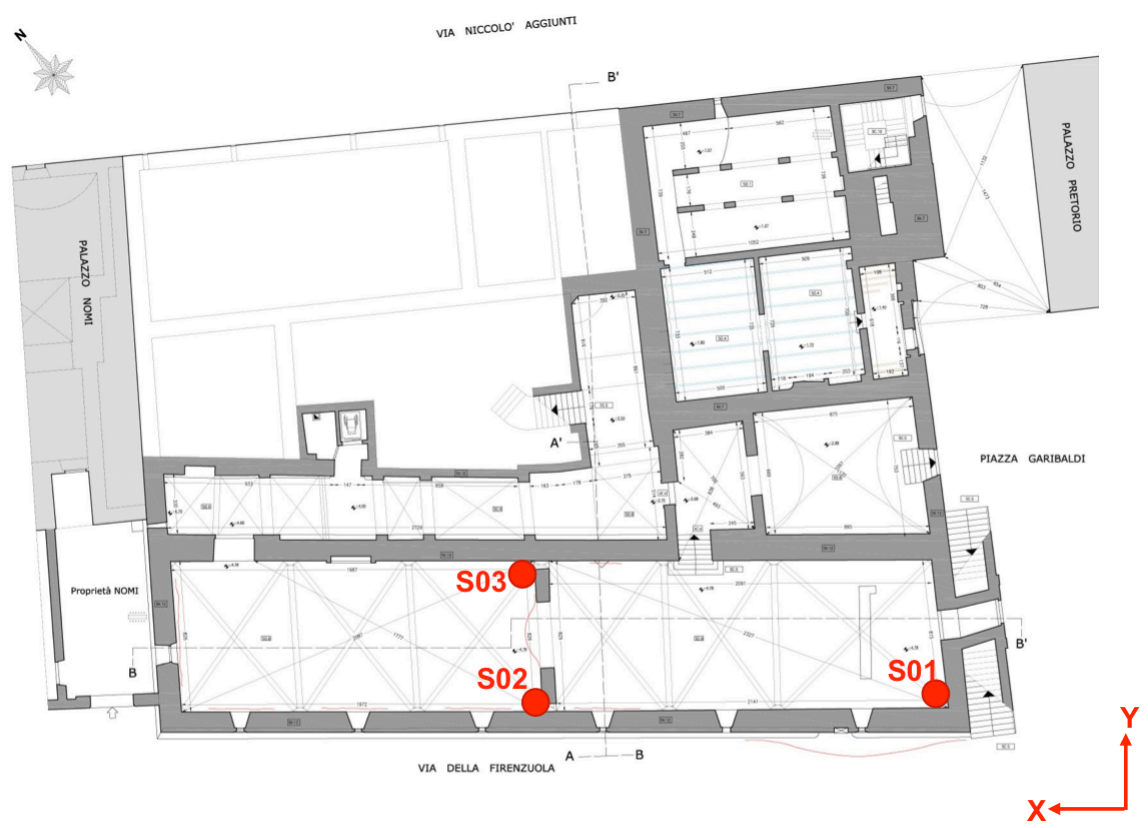

Figure 1. Position of 3 seismic stations installed at the ground level.

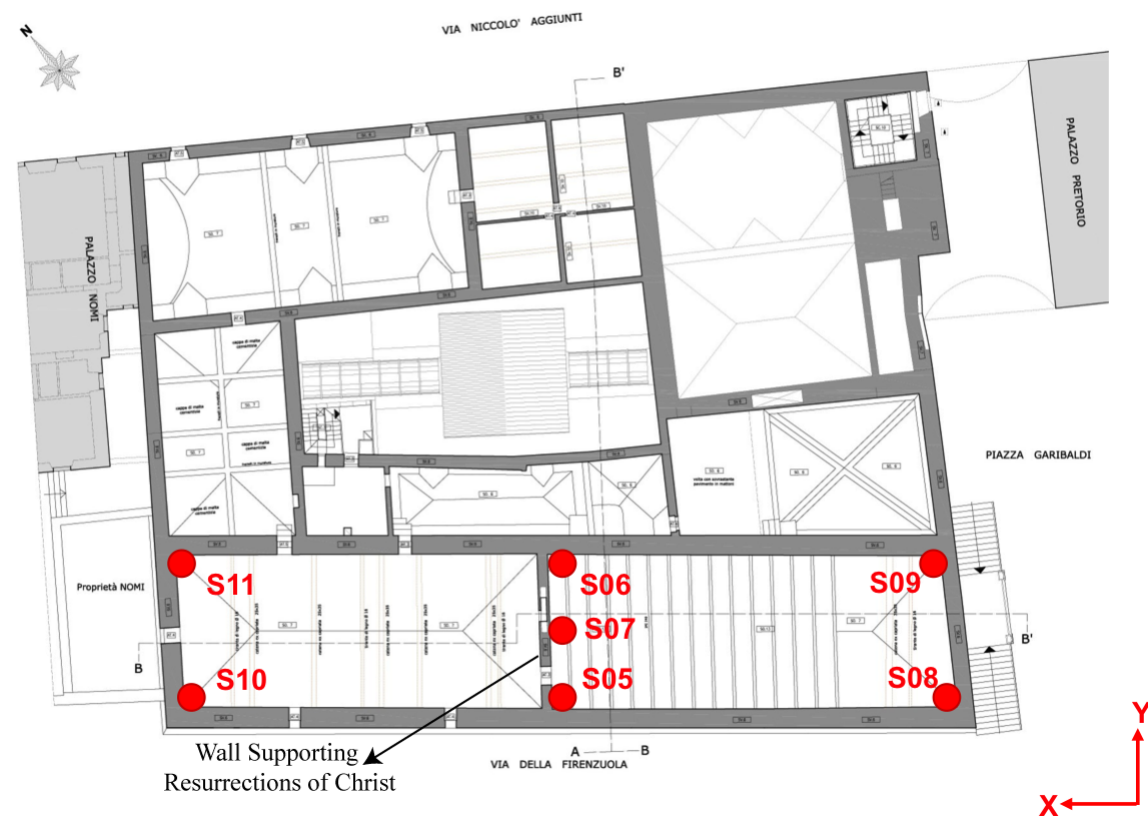

Figure 2. Position of 7 seismic stations installed at the roof of the museum. 


\section{AUTOMATIC OPERATIONAL MODAL ANALYSIS}

The enhanced frequency domain decomposition (EFDD) is a frequency domain technique for operational modal analysis of structures for which the theoretical background is described in numerous papers $[11,12,1314]$ and therefore we here only summarize the fundamental theoretical steps. The EFDD is an extension of the Basic Frequency Domain technique (BFD), often called Peak-picking method [16], and it is based on the Singular Value Decomposition (SVD) of the Power Spectral Density (PSD) matrix $\boldsymbol{G}_{\boldsymbol{y} y}(\boldsymbol{\omega})$, where $\boldsymbol{\omega}$ are the single angular frequency.

Here we used the automatic modal identification method first introduced by Brincker et al. (2007) [12] and implemented by Rainieri and Fabrocino (2010) [13] for computing automatically the modal parameters of the buildings. The main steps of automatic EFDD method applied in the present study can be summarized as follows.

\subsection{Spectral density matrix}

For all the signals in each $300 \mathrm{~s}$ long data set, the spectral density matrix $\boldsymbol{G}_{\boldsymbol{y y}}(\boldsymbol{\omega})$ is calculated using the Welch's technique with Hanning weighting function of $60 \mathrm{~s}$, an overlap of $66 \%$ and frequency resolution of $0.0122 \mathrm{~Hz}$. The Hanning function ensures that all data are equally weighted in the averaging process, minimizing leakage and ringing effects. The size of the matrix is in our case $30 \times 30$ for each frequency $\omega$ and where 30 are the total number of channels ( 3 components $x 10$ stations) used for the analysis of the seismic response of the museum.

\subsection{Single Value Decomposition (SVD)}

The SVD of the spectral density matrix $\boldsymbol{G}_{\boldsymbol{y y}}(\boldsymbol{\omega})$ is calculated to identify the modal shape by looking at which frequency the first singular value (Figure $3 \mathrm{c}$ ) has a peak $\left(\boldsymbol{\omega}_{\text {peak }}\right)$. At this frequency, the first singular vector is used to estimate the modal shape of the structure $[1,78]$.

\subsection{Automatic Identification of Modal Domain}

The modal shapes are automatically searched within the modal domain (or modal bandwidth) using the modal coherence $[13,14]$. The latter is evaluated between each frequency line of two first singular vectors calculated for two consecutive records $300 \mathrm{~s}$ length. The modal coherence will be 1 for stationary signals and will allow to define the modal domain due to the structural modes (Figure 3ab). The mean of $>0.96$ (Figure 3a) and the standard deviation of $<0.01$ (Figure $3 b$ ), calculated for a set of 10 consecutive modal coherences are used to reduce the noise and to identify the modal domain $[23,30]$. This procedure is repeated every $300 \mathrm{~s}$ and for the entire record.

\subsection{Automatic Identification of Modal Shape.}

Within each modal bandwidth (Figure 3c), the maximum amplitude of the first singular value will correspond to the modal frequency. For this frequency peak, the corresponding first singular vector $\mathbf{u}_{\mathbf{1}}$ provides the modal shape $\boldsymbol{\varphi}_{\boldsymbol{r} \text {,jmode }}=\left\{\mathbf{u}_{\mathbf{1}}\left(\boldsymbol{\omega}_{\text {peak,jmode }}\right)\right\}$ every $300 \mathrm{~s}$ long data set. 


\subsection{Natural Frequency and Damping}

The natural frequency and damping of each mode is then evaluated interpreting each amplification region in the first singular value line as the spectral bell of the power spectral density [17] of a Single Degree of Freedom (SDOF) system. The spectral bell is calculated using a MAC (Modal Assurance Criterion) rejection level of 0.9 of the modal shape $\boldsymbol{\varphi}_{\boldsymbol{r} \text {,jmode }}$ and then it is converted in the time domain to estimate the so-called normalized correlation function. The resonance frequency of the structure is then simply obtained by counting the number of times the normalized correlation function crosses the zero axis per second [17]. Whereas, the damping is calculated by using the logarithmic decrement technique of the normalized correlation function (Figure 6c).

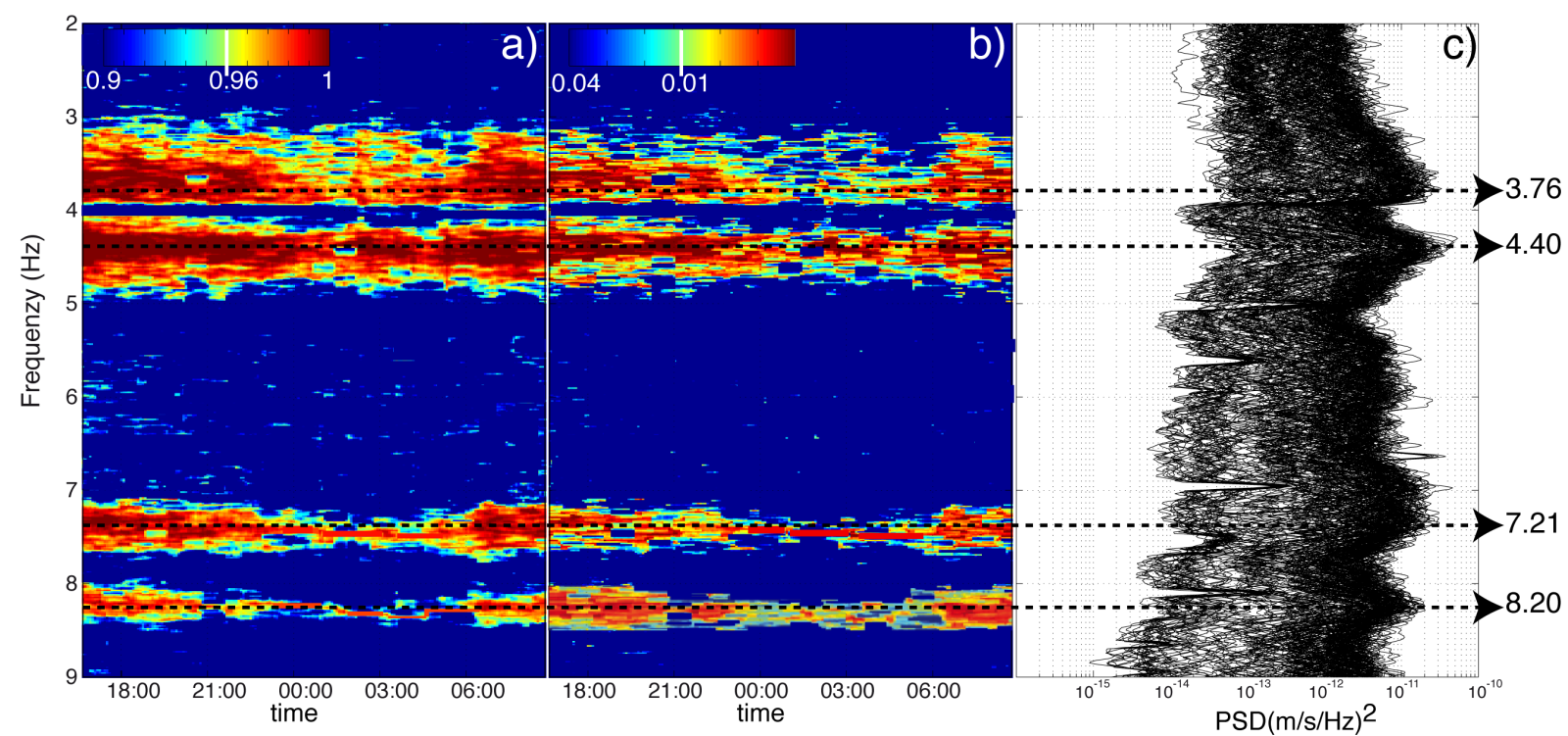

Figure 3. The automatic EFDD technique is based on detecting the modal bandwidth using the mean a) and the standard deviation $b$ ) of the modal coherence calculated during the seismic survey on 10 consecutive records, the white lines on the both colour bars represent the thresholds $>0.96$ and $<0.01$ used for the identification of mode bandwidth for mean a) and standard deviation of modal coherence b), respectively. c) first singular values estimated for all the observation time (17 hours). 


\section{MODAL PARAMETERS OF THE MUSEUM}

The EFDD method has automatically identify the first four modes of the Sansepolcro Museum with structural frequency at $3.76 \mathrm{~Hz}, 4.40 \mathrm{~Hz}, 7.21 \mathrm{~Hz}$ and $8.20 \mathrm{~Hz}$ (Figure 3).

Figure 4 shows the three-dimensional representation of the four modes. The Museum is characterized by a first and second transversals modes with a movement trend in NE-SW direction, with a frequency of $3.76 \mathrm{~Hz}$ and $4.40 \mathrm{~Hz}$, respectively (Figure 4). The third modal shape, at frequency of $7.21 \mathrm{~Hz}$, presents a transversal movement in out of phase of the external walls in NW-SE direction (Figure 4). The fourth mode is torsional with a frequency of $8.20 \mathrm{~Hz}$ (Figure 4). The wall, supporting the mural painting the Resurrection of Christ, follows the movement of the building with amplitude lower than the lateral and external walls, for all the four modal shapes.
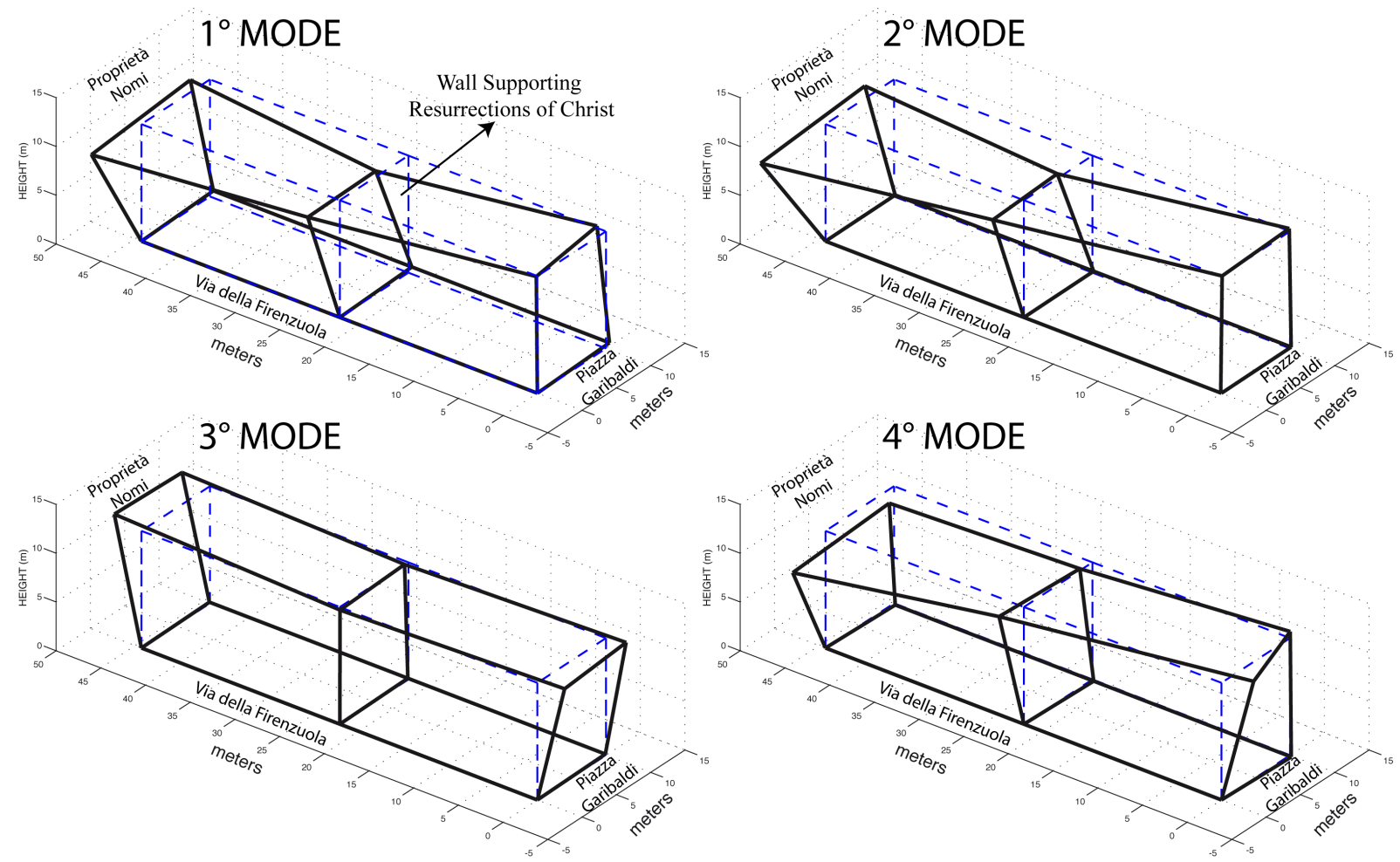

Figure 4. Three-dimensional representation of the four modes

The overall dynamic behavior of the Museum can be then represented in terms of structural frequencies (Figure 5a), damping ratios (Figure 5b) and absolute displacements (Figure 5c) for the four modal shapes. The building show larger values of damping ratios of the first and second modes than the third and fourth modes which are, for the whole 17 hours long period of observation, less than $1 \%$ (Figure $5 b$ ).

To assess the absolute value of the movement of each modal shape of the Museum as induced by the very low level ambient noise excitation, we calculate the displacement in $\mu \mathrm{m}$ by i) integrating the ground seismic velocity and ii) filtering in a $1 \mathrm{~Hz}$ bandwidth around the natural frequency of each mode (Figure 3c). The maximum absolute displacement of the single modal oscillation is then calculated in a $20 \mathrm{~s}$ time window. Displacement here represents (Figure 5c) the absolute movement in $\mu \mathrm{m}$ relative to the equilibrium position and allows to assess the influence of each modal shape on the dynamics of the structure. The first mode (black line Figure 5c) induce a displacement of $\sim 0.3 \mu \mathrm{m}, 3$ time larger than those produced by the $4^{\text {th }}$ mode 
(magenta line Figure 5c). Besides, displacements for each mode show a remarkable decrease during night-time (from 23:00 to 05:00 GMT) ten times smaller than during the day-time, indicating the high sensitivity of the seismic sensors and EFDD technique to detect the dynamic response of the building by the very low amplitude of the ambient vibration.

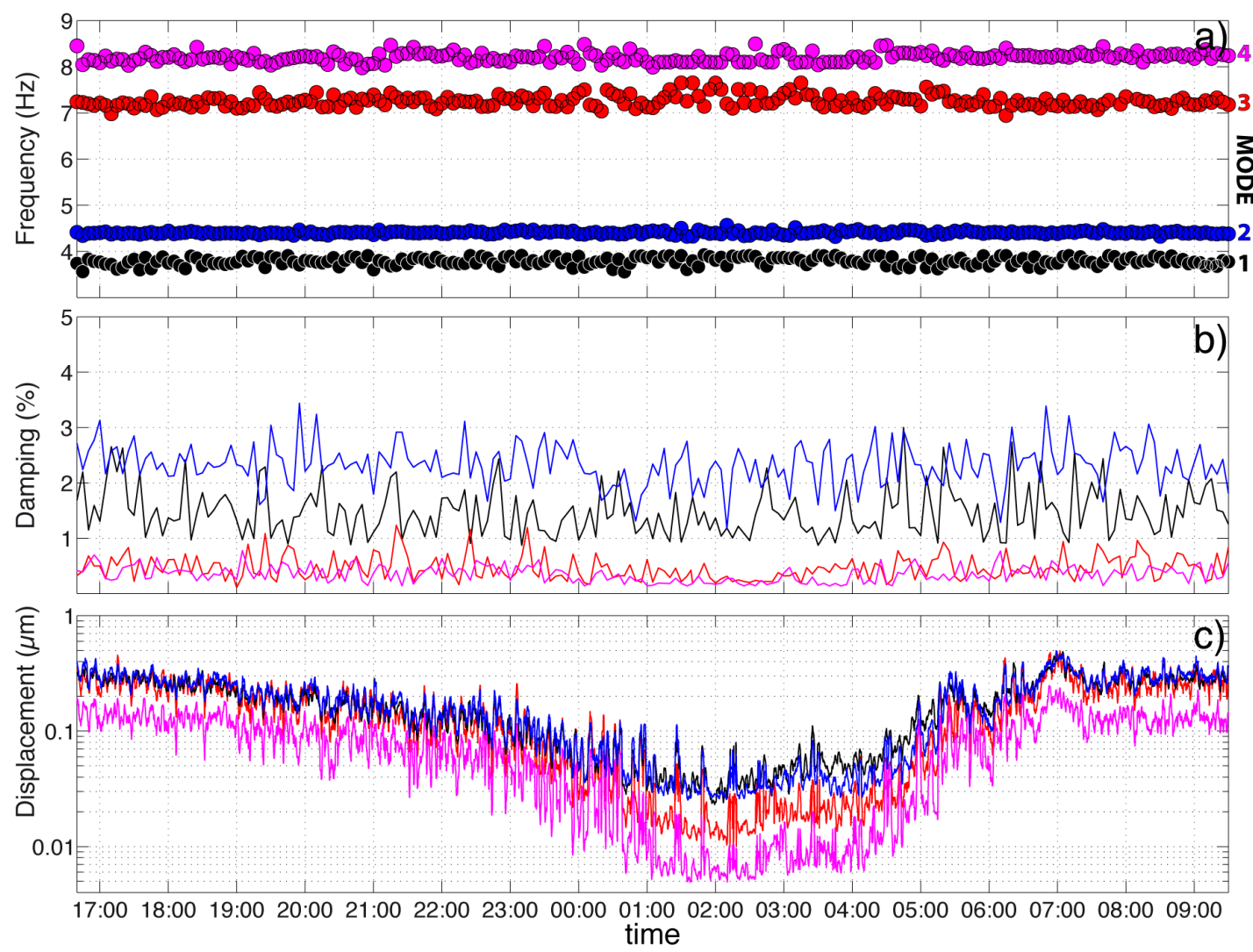

Figure 5. a) Trend over time of the structural frequencies, b) trend over time of the Damping ratio for each modal shape, c) trend over time of the displacement for each modal shape of the museum of Sansepolcro. 


\section{CONCLUSIONS}

An experimental seismic survey with ambient vibrations has been carried out on the Museum of Sansepolcro containing the famous mural painting Resurrection of Christ by Piero della Francesca. Ten seismic stations were installed along the building recording the ambient vibrations due to anthropic activity. The seismic signals were analyzed in frequency domain using the EFDD method. Four main frequencies were identified with the associated modal shapes, damping and displacement.

The modal parameters were used to calibrate a numerical 3D finite element SAP2000 to identify the elastic modulus of the masonry [ 15 - this volume], by an iterative procedure that minimizes the difference between experimental and numerical modal results (Table 1).

Integrating, the results of the dynamic identification with 3D FEM model analysis, has extended the knowledge of the structural behavior of entire building and consequently of the wall supporting the Resurrection of Christ.

The wall supporting the fresco is embedded in the middle of central wall-panel and confined by the lateral walls with soft links [15], this system connections between the walls explains its limited movement respect to the lateral and external walls of the building, as detected by dynamic identification and confirmed by the numerical model.

Our results indicate clearly that the operational Modal analysis using ambient vibrations provides detail information on dynamic response of the building, useful to derive reliable model with respect to their real dynamic behavior for structural analysis.

\begin{tabular}{|c|c|c|}
\hline Mode Number & Experimental Frequency (Hz) & Numerical Frequency (Hz) \\
\hline 1 & 3.766 & 3.765 \\
\hline 2 & 4.405 & 4.876 \\
\hline 3 & 7.217 & 7.318 \\
\hline 4 & 8.204 & 8.264 \\
\hline
\end{tabular}

Table 1. Comparison between numerical and experimental modal frequencies.

\section{REFERENCES}

[1] Brincker, R., Zhang, L., and Andersen, P., "Modal Identification from Ambient Response Using Frequency Domain Decomposition," Proc. of the 18th International Modal Analysis Conference, San Antonio,TX, February 7-10, 2000.

[2] Cunha, E. and Caetano, A. 2005 Experimental modal analysis of civil engineering structure. First international modal analysis conference, IOMAC, Copenhagen, Denmark.

[3] Rainieri, C., Fabbrocino, G., Cosenza, E. 2007b. Automated Operational Modal Analysis as structural health monitoring tool: theoretical and applicative aspects. Key Engineering Materials. Vol. 347. pp. 479- 484.

[4] Andersen P., R. Brincker, M. Goursat and L. Mevel, Automated Modal Parameter Estimation For Operational Modal Analysis of Large Systems, Proceedings of the 2nd In- 
ternational Operational Modal Analysis Conference, Copenhagen, Denmark, 2007, Vol. 1, pp. 299-308.

[5] Trifunac MD (1972) Comparisons between ambient and forced vibration experiments. Earthq Eng Struct Dyn 1:133-150.

[6] Gentile, C. (2005). Operational Modal Analysis and Assessment of Historical Structures, Proceedings of the 1st IOMAC Conference, Copenhagen, Denmark.

[7] Brincker, R., Zhang, L. and Andersen, P. 2001 Modal identification of output-only systems using frequency domain decomposition. Institute of Physics Publishing, Smart materials and structures, 10,441-445.

[8] Brincker, R, Ventura, C. and Anderson P. 2003 Why output-only modal testing is a desirable tool for a wide range of practical applications. 21st International Modal Analysis Conference IMAC, Kissimmee, Florida

[9] Hearn G., R.B. Testa, Modal analysis for damage detection in structures, Journal of Structural Engineering 117 (1991) 3042-3063.

[10] Gentile C., A. Saisi, Ambient vibration testing of historic masonry towers for structural identification and damage assessment, Constr Build Mater 21 (6) (2007) 1311-1321.

[11] Brincker R., P. Andersen and N. J. Jacobsen: Automated Frequency Domain Decomposition for Operational Modal Analysis; in Proceedings of the 25th SEM International Modal Analysis Conference, Orlando, Florida, USA, February 19-22 2007

[12] Fabbrocino G., C. Rainieri and E. Cosenza, Automated Operational Modal Analysis solutions for continuous seismic monitoring, in Proceedings of IASS 2007, Venice, Italy, 2007.

[13] Rainieri C., G. Fabrocino, Automated output-only indentification of civil engineering structures, Mechanical Systems and Signal Processing 24 (2010) 678-695.

[14] Lacanna G., M. Ripepe, E. Marchetti, M. Coli, C.A. Garzonio. Dynamic response of the Baptistery of San Giovanni in Florence, Italy, based on ambient vibration test, Journal of Cultural Heritage, 2016, http://dx.doi.org/10.1016/j.culher.2016.02.007 .

[15] Coli M., M. Micheloni. Structural analysis of the walls supporting the Resurrection of Christ by Piero della Francesca mural painting at Sansepolcro, Italy. COMPDYN 2019, $7^{\text {th }}$ ECCOMAS Thematic conference on computational methods in Structural dynamics and earthquake engineering, Crete, Greece, 24-26 June 2019.

[16] Bendat JS, Piersol AG (1993) Engineering applications of correlation and spectral analysis.Wiley, New York

[17] R. Brincker, C. Ventura, P. Anderson: Damping estimation by frequency domain decomposition: Proceedings of the $19^{\text {th }}$ International Modal Analysis Conference, Kissimmee, Florida, February 5-8, 2001, 698-703. 